\title{
Calculation of Residual Surface Subsidence Above Abandoned Longwall Coal Mining
}

\author{
Ximin Cui ${ }^{1, *}$, Yuling Zhao ${ }^{1,2, *}$, Guorui Wang ${ }^{1,3}$, Bing Zhang ${ }^{4}$ and Chunyi Li $^{5}$ \\ 1 Institute of Geoscience and Surveying Engineering, China University of Mining and Technology (Beijing), \\ Beijing 100083, China; wgrcumtb@163.com \\ 2 Institute of Mining and Surveying, Hebei University of Engineering, Handan 056038, China \\ 3 Land Resources Survey and Monitoring Institute of Ningxia Hui Autonomous Region, \\ Yinchuan 750002, China \\ 4 School of Resources and Environmental Science, Shijiazhuang University, Shijiazhuang 050035, China; \\ zhbing1020@126.com \\ 5 School of Surveying and Land Information Engineering, Henan Polytechnic University, Jiaozuo 454000, \\ China; lichunyi@hpu.edu.cn \\ * Correspondence: cxm@cumtb.edu.cn (X.C.); zhaoyuling@hebeu.edu.cn (Y.Z.); \\ Tel.: +86-010-62339996 (X.C.); +86-13393108130 (Y.Z.)
}

Received: 1 February 2020; Accepted: 17 February 2020; Published: 18 February 2020

\begin{abstract}
Exhausted or abandoned underground longwall mining may lead to long-term residual subsidence on surface land, which can cause some problems when the mined-out land is used for construction, land reclamation and ecological reconstruction. Thus, it is important to assess the stability and suitability of the land with a consideration of residual surface subsidence. Assuming a linear monotonic decrease in the annual residual surface subsidence, the limit of the sum of the annual residual subsidence factor, and continuity between surface subsidence in the last year of the weakening period and the residual surface subsidence in the first year, we establish a model to calculate the duration of residual subsidence and the annual residual surface subsidence factor caused by abandoned longwall coal mining. The duration of residual surface subsidence increases with the increase in mining thickness as well as the factor of extreme residual subsidence. The proposed method can quantitatively calculate the annual residual subsidence, the accumulative residual subsidence, and the potential future accumulative residual subsidence. This approach can be used to reasonably evaluate the stability and suitability of old mining subsidence areas and will be beneficial for the design of mining subsidence land reclamation and ecological reconstruction.
\end{abstract}

Keywords: longwall coal mining; residual surface subsidence; quantitative prediction; stability; land reclamation; ecological reconstruction

\section{Introduction}

During underground longwall mining, the equilibrium conditions in the overburden strata are disturbed. As the working face advances, the roof strata bend downward. Then, when the excavated area expands to a sufficient size, the roof strata will cave. As a result, the overlying strata continue to bend and break until the fallen rock fragments are sufficiently high to support the overhanging strata. At this time, the overhanging strata above the caved zone no longer cave but are replaced by fractured or bending and resting on the underlying strata. Strata bending and subsidence develop upward until they reach the surface and form a subsidence basin. The overburden strata and surface subsidence basin will then undergo a period of compaction before gradually becoming stable [1]. Subsidence development and subsidence velocity curves for a surface point are shown in Figure 1. The total duration of surface movement development can be divided into three periods. The initial 
period comprises surface subsidence of up to $10 \mathrm{~mm}$, with a subsidence velocity of up to $50 \mathrm{~mm} / \mathrm{month}$ or $1.7 \mathrm{~mm} /$ day. The second period is named the active period, characterized by surface subsidence velocities of greater than $50 \mathrm{~mm} / \mathrm{month}$ or $1.7 \mathrm{~mm} /$ day. The third period is named the weakening period, typified by subsidence velocities of less than $50 \mathrm{~mm} / \mathrm{month}$ or $1.7 \mathrm{~mm} /$ day. This period ends when less than $30 \mathrm{~mm}$ of accumulative surface subsidence occurs in 6 months, which indicates stabilized surface movement [2-4]. During the active movement period, the amount of subsidence accounts for more than $85 \%$ of the total subsidence. Thus, the surface movement from the initial period to the weakening period has received considerable attention around the world. Both final and progressive surface subsidence predictions have been conducted in order to prevent mining damage and to estimate the uncertainty and reliability of subsidence predictions [5-10]. However, field measurements in China showed that surface subsidence after the weakening period is not completely stable, but it grows slowly and gradually [11-13]. Radar-interferometry data analysis of the Houthalen coal mine in Belgium revealed that residual downward movement occurred for 7-12 years after its closure in 1992. The average observed residual subsidence rate was $5.5 \mathrm{~mm} / \mathrm{a}$ and the maximum was $30 \mathrm{~mm} / \mathrm{a}$ [14]. Therefore, the residual surface subsidence may decrease gradually and last for several years or even decades, despite a very small amount of residual surface subsidence, as shown in Figure 1.

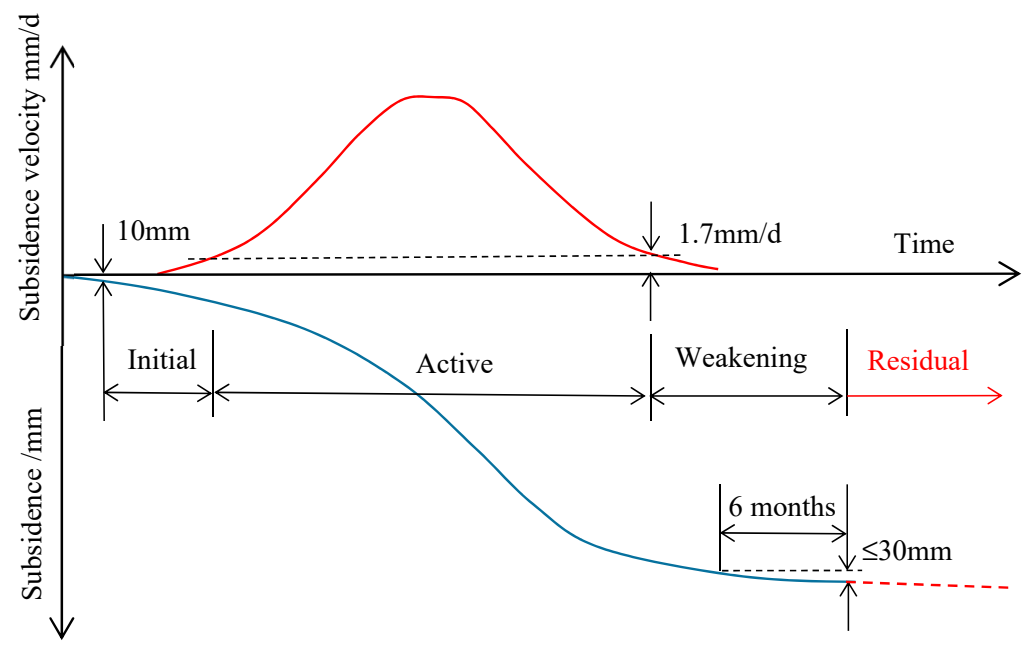

Figure 1. Sketch map of subsidence development and subsidence velocity curves for a surface point.

In recent years, considerable attention has been devoted to the residual subsidence and influencing factors at abandoned coal mines [15]. Abandoned mine works are a potential cause of ground subsidence and hence are of major concern where development or re-development is to take place. In the United Kingdom, information necessary to locate potential hazards may be available but occurs in numerous scattered locations, and it may require considerable time to access the data [16]. The surface subsidence in an adjacent working coal face may be influenced by an abandoned goaf [17]. The room and pillar stability problems associated with a shallow, abandoned ironstone mine have been analyzed in detail using empirical approaches [18]. In order to monitor the residual subsidence, differential Interferometry SAR (DInSAR), Persistent Scatterer Interferometry (PSI) and the integration of DInSAR and SBAS Techniques were used to determine mining-related deformations; the root-mean-square error (RMSE) between the modeled and measured deformation by InSAR was found to be 11 and $13 \mathrm{~mm}$ for vertical and horizontal displacements, respectively [19-21]. Since ground subsidence around abandoned underground coal mines can cause much loss of life and property, GIS-based ground subsidence hazard mapping of abandoned coal mines has been researched. The frequency ratio model and sensitivity analysis were employed to determine the importance of extracted subsidence-related factors [22,23]. Tunneling and transport infrastructure in abandoned coal mine areas have also been studied by FLAC 3D numerical modelling in order to assess and reduce the geo-hazards [24,25]. Coal mining unfortunately tends to make a notable impact on the environment, the impacts varying 
in severity depending on whether the mine is working or abandoned, the mining methods used, and the geological conditions [26-29]. An interdisciplinary approach employing hydrology, geographic information systems, and a recreation visitation function model was used to estimate the costs of abandoned coal mine reclamation [30].

With continued urbanization, the need for the reclamation of mining subsidence areas is becoming increasingly urgent, especially in China. In many mining cities, such as Pingdingshan, Tangshan, Xuzhou, Yanzhou, Fuxin, Benxi, Fushun, Huainan, Zaozhuang, Pingxiang, Zibo, and Zhangjiakou, the reuse of mining subsidence land for construction has been widely carried out. In order to evaluate the stability and suitability of old mining subsidence areas, the factor of residual surface subsidence is a major parameter that must be considered. The factor value of the residual mining subsidence is selected empirically according to mining depth, properties of overburden strata, and the completion date of longwall mining, then the amount of residual surface subsidence is predicted based on the probabilistic integral method [31-33]. However, the accuracy of the resulting prediction is insufficient; it does not quantitatively determine the annual residual subsidence, the accumulative residual subsidence, or the potential future accumulative residual subsidence, nor does it objectively provide the duration of residual subsidence. Therefore, with the aim of providing an objective and quantitative prediction of residual surface subsidence, this study analyzes the factor of residual surface subsidence and subsidence duration for old longwall coal mining.

\section{Method for Calculating the Residual Subsidence Factor and Duration}

\subsection{Factor of Extreme Residual Subsidence}

After sufficient extraction of a longwall panel section, the overburden strata display various degrees of movement. According to the movement characteristics, the fractured overburden strata can be divided into four zones, as illustrated in Figure 2 [1,34].

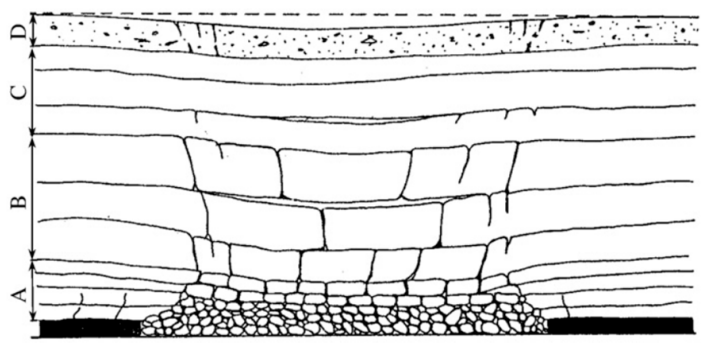

Figure 2. Zones of strata movement above a longwall panel.

- Caved zone A: After coal extraction, the immediate roof strata caves irregularly and falls into the void. The strata in this zone behave not only with complete discontinuity, but also all stratified bedding is loosed. The caved zone is normally two to eight times larger than the mining height, depending on the properties of the immediate roof and overburden strata.

- Fractured zone B: Strata breakage and discontinuity present the basic characteristics in this zone area, while the rock retains stratified bedding. The strata breakage gradually reduces upwards, resulting in a decrease in fracture network development and, of course, the permeability in the strata. The combined height of the fractured zone with the caved zone is about 20 to 30 times the mining height in hard or strong rock; 12 to 15 times the mining height in medium hard rock; and nine to 11 times the mining height in soft or weak rock, respectively. That is to say, the height of the fractured zone in hard and strong strata is greater than that in soft and weak rock.

- Continuous bending or deformation zone C: The strata above the fractured zone deflect downward without apparent breaking. The strata continuity and their original stratified features remain. In some cases, impermeability is temporarily lost but resumed soon after. Some opening fissures may appear in the tension zone but, in general, the strata maintain continuity. 
- Soil zone D: This is the surface layer, the depth of which depends on location. It consists of soil and weathered rocks. Depending on the physical properties of soils, cracks may open up when the face is nearby and close back when the face is far away. However, some cracks, especially those along the edges of the panel, may remain open after mining but the crack walls collapse easily to fill up the cracks.

Bulking is a volume increase phenomenon that occurs when intact rock is broken [35]. Caving of a mine roof may cease when the gap from the floor to the roof is filled with broken or loose material. The bulking factor of the broken material then determines the height of the caved zone. When this material is subjected to stress, two main parameters control its compaction process: the initial bulking factor and the strength of the rock fragments. The initial bulking factor is typically greater than one because the volume of broken roof rocks is larger than that of the original intact strata. It varies with the shape of the fragments, their size, and size distribution, as well as the configuration of the caved rock fragments. The in situ measurements indicate that the bulking factor decreases with increasing size, size range, and shape regularity of the fragments. The bulking factor of stronger and harder rocks is smaller because they result in larger fragments; conversely, weaker and softer rocks result in smaller fragments and consequently a larger bulking factor. The initial compaction of such bulked material is larger at the initial loading stage. It is impossible to compress the material back into its original intact volume; however, the compaction of such material to its original volume may be possible under infinite pressure [36]. Based on this assumption, the extreme residual surface subsidence factor $q_{m}$ can be expressed as

$$
q_{m}=n(1-q)
$$

where $q$ is the surface subsidence factor, which ranges from 0.65 to 0.90 in China; $n$ is the coefficient related to the compaction of caved or broken rock, $0<n \leq 1$. If $n=1$, the material has been compressed back into its original intact volume. When there are no in situ observations for the coefficient related to the compaction of caved or broken rock, $n=0.5$ is selected for a middle way generally.

\subsection{Determination of Annual Residual Surface Subsidence Factor}

Compared with the development of normal surface subsidence, the residual subsidence is smaller, and its duration is longer. According to the law of residual surface subsidence, the annual residual surface subsidence decreases gradually with time in the duration, and the sum of the factor of annual residual surface subsidence must equal the factor of extreme residual surface subsidence. Assuming the duration of residual subsidence is $T_{r}$, the annual residual subsidence factor $q_{A}^{t}$ satisfies the following two conditions:

$$
\begin{gathered}
\sum_{t=1}^{t=T_{r}} q_{A}^{t}=q_{m} \\
q_{A}^{1}>q_{A}^{2}>q_{A}^{3}>\ldots>q_{A}^{T_{r}}
\end{gathered}
$$

where $q_{A}^{1}, q_{A}^{2}, \ldots, q_{A}^{T_{r}}$ are the factors of annual residual subsidence of the first year, second year, $\ldots$, and $T_{r}$ year, respectively.

Since the annual residual surface subsidence factor is smaller and decreases gradually with time, a linear monotonic decrease in the residual subsidence factor is accepted. Thus, we have

$$
\begin{gathered}
q_{A}^{1}=q_{m} T_{r} / \sum_{t=1}^{t=T_{r}} t \\
q_{A}^{2}=q_{m}\left(T_{r}-1\right) / \sum_{t=1}^{t=T_{r}} t \\
\ldots \ldots \ldots \ldots \ldots \ldots \ldots \ldots . \ldots . \ldots . \ldots . \ldots \\
q_{c}^{T_{c}}=q_{m} / \sum_{t=1}^{t=T_{r}} t
\end{gathered}
$$


Then, the following normalized expression for the annual residual surface subsidence factor $q_{A}^{t}$ can be obtained from Expression (4).

$$
q_{A}^{t}=q_{m} \frac{2\left(T_{r}-t+1\right)}{T_{r}\left(T_{r}+1\right)}, t=1,2,3, \ldots, T_{r}
$$

According to Expression (5), we can prove that the restrictive conditions of Expressions (2) and (3) are satisfied.

\subsection{Duration of Residual Surface Subsidence}

As shown in Figure 1, the requirement for the end of the weakening period is less than $30 \mathrm{~mm}$ of surface subsidence in 6 months. Subsequently, we can deduce that the amount of surface subsidence in the final year of the weakening period is greater than $60 \mathrm{~mm}$. In order to maintain the continuity of surface subsidence, the residual subsidence in the first year must be smaller than that in the final year of the weakening period. Thus, we obtain

$$
m q_{A}^{1} \cos \alpha=\frac{m q_{m} \cos \alpha T_{r}}{\sum_{t=1}^{t=T_{r}} t} \leq 60
$$

where $m$ is the mining thickness (mm); $\alpha$ is the dip angle of the coal seam; and $T_{r}$ is the duration of residual surface subsidence (a). Expression (6) can also be rewritten as

$$
T_{r} \geq \frac{m q_{m} \cos \alpha}{30}-1
$$

When the duration of residual surface subsidence $T_{r}$ is determined by Expression (7), the annual residual surface subsidence factor $q_{A}^{t}$ can be calculated easily by Expression (5). It must be noted that although the duration of $T_{r}$ calculated by Expression (7) may be a decimal, an integer of year is demanded. As shown in Expression (7), if the calculated duration of $T_{r}$ is 3.2a, it is 4a under the condition of large and equal in practice.

\subsection{Discussion}

As shown in Expression (7), the duration of residual surface subsidence is predominantly related to the mining thickness and the factor of extreme residual subsidence. In order to qualitatively analyze the duration of residual subsidence, we select coal mining thicknesses of 1.5, 2, 2.5, 3, 3.5, 4, and $4.5 \mathrm{~m}$, respectively, and surface subsidence factors of $0.7,0.75,0.8,0.85,0.9$, and 0.95 , respectively. The coefficient related to the compaction of caved or broken rock is 1 and the dip angle of the coal seam is $0^{\circ}$. The distribution of the residual subsidence duration is shown in Figure 3, indicating a linear increase in the duration with the increasing of mining thickness for the same factor of extreme residual subsidence. The duration also increases linearly with the increasing of the factor of extreme residual subsidence for the same mining thickness. With other conditions kept constant, and only the coefficient related to the compaction of caved or broken rock reduced to 0.5 , the duration of residual subsidence decreases (Figure 4). Thus, the duration of residual surface subsidence can be quantitatively determined once the mining thickness and the factor of extreme residual subsidence are known for specific geo-mining conditions.

In order to calculate the factor of annual residual subsidence, the duration of residual surface subsidence is employed as a minimum integer that satisfies Expression (7). For the factor of an extreme residual surface subsidence, $q_{m}$, of 0.2 , the distribution of the annual residual subsidence factor for different mining thickness is shown in Figure 5. The larger the mining thickness, the longer the duration of residual subsidence. The thinner the mining thickness, the larger the residual subsidence factor in the first year. For instance, the duration of residual subsidence for a mining thickness of $1.5 \mathrm{~m}$ is $9 \mathrm{a}$, and the annual residual subsidence factor is $0.04,0.036,0.031,0.027,0.022,0.018,0.013,0.009$, and 0.004 
from the first year to the last year, respectively. The sum of the annual residual subsidence factor is 0.2 , which equals $q_{m}$.

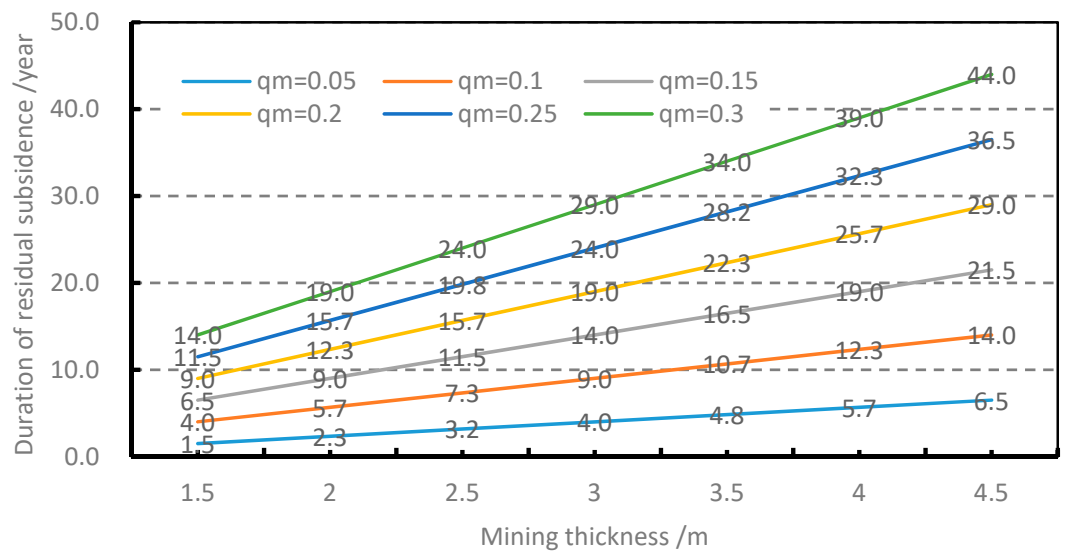

Figure 3. Duration of residual subsidence for $n=1$ (where $n=$ the coefficient related to the compaction of caved or broken rock and $q_{m}=$ the factor of extreme residual surface subsidence).

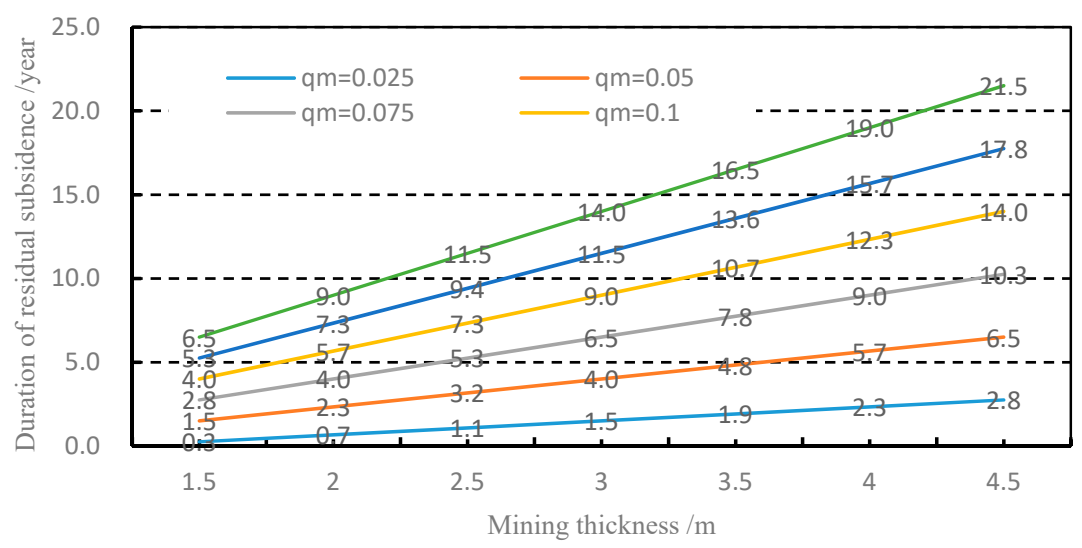

Figure 4. Duration of residual subsidence for $n=0.5$ (where $n=$ the coefficient related to the compaction of caved or broken rock and $q_{m}=$ the factor of extreme residual surface subsidence).

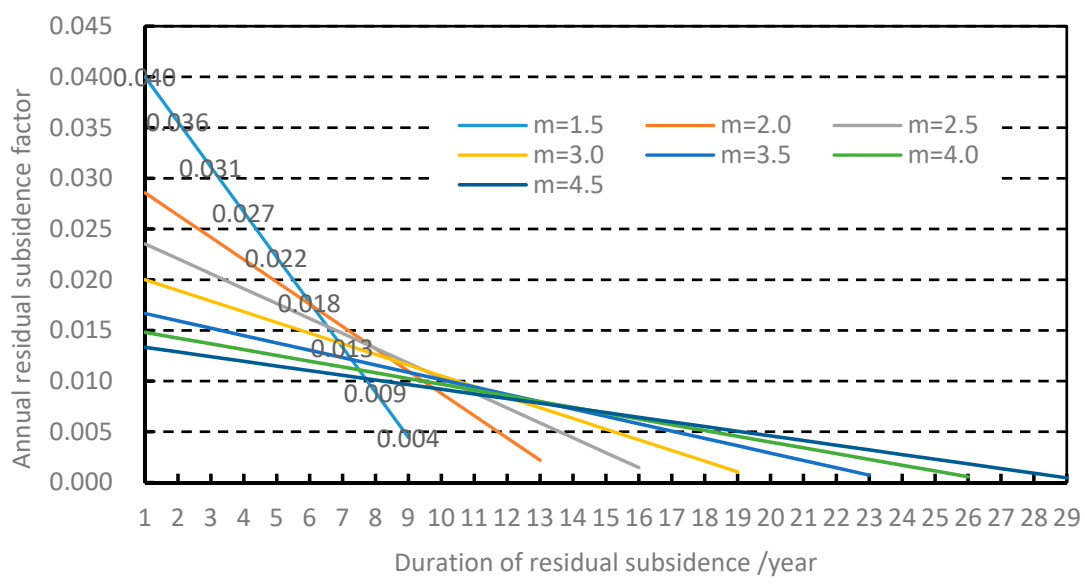

Figure 5. Factors of annual residual subsidence for $q_{\mathrm{m}}=0.2$ (where $q_{m}=$ the factor of extreme residual surface subsidence and $m$ is the mining thickness).

Figure 6 shows the factors of annual residual subsidence related to different $q_{m}$ values for a mining thickness of $3 \mathrm{~m}$. The residual subsidence factors in the first year are all equal. The duration of residual 
subsidence is 9 a for $q_{m}=0.1$ and the annual residual subsidence factors are $0.02,0.018,0.016,0.013$, $0.011,0.009,0.007,0.004$, and 0.002 from the first year to the last year, respectively. The sum of the annual residual subsidence factor is 0.1 , which also equals $q_{m}$. The above analysis demonstrates that the duration of residual subsidence and the factor of annual residual subsidence can be quantitatively determined when the mining thickness and the factor of extreme residual subsidence are known.

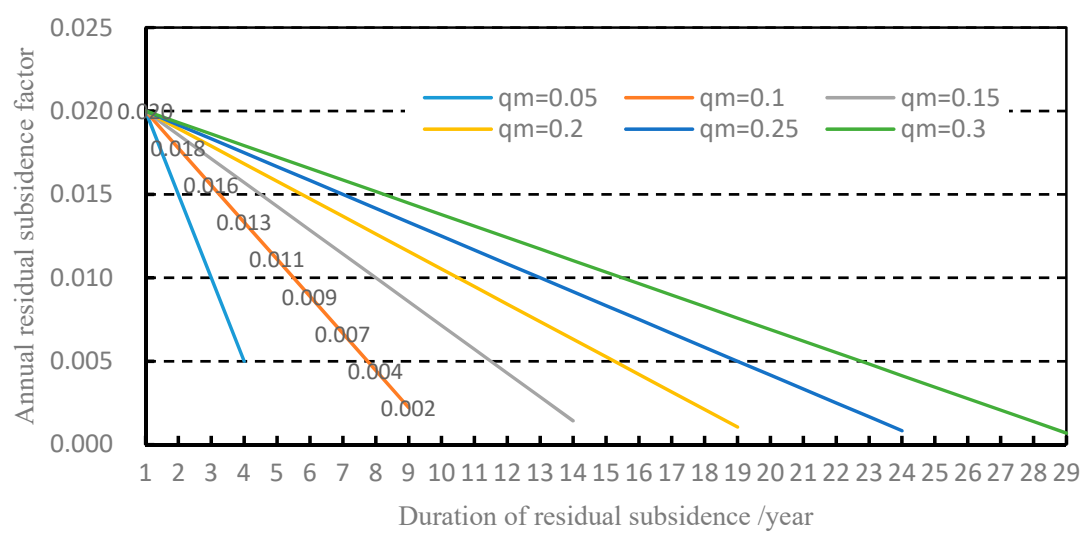

Figure 6. Factors of annual residual subsidence for $m=3.0 \mathrm{~m}$ (where $q_{m}=$ the factor of extreme residual surface subsidence and $m$ is the mining thickness).

In 2014, an industry standard known as the subsidence prediction method for coal mining was proposed by the China Technical Identification Committee for Coal Mining Damage [37]. The formula to calculate the annual residual surface subsidence factor is given as

$$
q_{A}^{t}=k(1-q)\left(1-e^{-\left(\frac{50-t}{50}\right)}\right)
$$

where $k$ is a coefficient similar to $n, k=0.5-1.0 ; t$ is the time after mining completion (a). According to Expression (8), only at $t=50$ can the annual residual subsidence factor decrease to $q_{A}^{50}=0$. Thus, a duration of residual surface subsidence of 50a is always used, regardless of different geo-mining conditions. The accumulative annual residual subsidence factor calculated with Expression (8) can be up to $18.077 k(1-q)$, which is far beyond the theoretical value of $k(1-q)$. Compared with the results of Expression (8), Expressions (5) and (7) established in this study are more reasonable and objective.

\section{Simulation and Analysis}

\subsection{Colliery Simulation}

The conditions of the colliery simulation are as follows: mining thickness, $m$, is $2 \mathrm{~m}$, dip angle of the coal seam, $\alpha$, is $0^{\circ}$, and the average mining depth, $H_{0}$, is $438 \mathrm{~m}$ with a medium hard overburden. The longwall coal mining was completed in 2010 and the mined-out panels have reached supercritical mining. The surface subsidence factor, $q=0.7$, is determined by processing the results of field measurements. According to a previous study, the duration of surface subsidence is determined by the regulations of coal mining under buildings, water bodies, railway and safety pillar design [38].

$$
T=2.5 H_{0}=1095 \text { days }=3 \text { a. }
$$

Accordingly, surface movement will cease three years after mining completion and residual surface subsidence will begin in 2014. Based on the safety design, the limit value of the coefficient $n=1$ is selected and the extreme residual surface subsidence factor is given as $q_{m}=0.3$. Using Expression (7), the duration of residual surface subsidence is determined as $T_{r}=19 \mathrm{a}$. The calculated factors of annual residual surface subsidence vs. time is shown in Table 1. 
Table 1. Calculated factors of annual residual surface subsidence for the colliery simulation.

\begin{tabular}{ccc}
\hline Year & Annual Residual Subsidence Factor & Annual Residual Subsidence/mm \\
\hline 2014 & 0.030 & 60 \\
2015 & 0.028 & 58 \\
2016 & 0.027 & 54 \\
2017 & 0.025 & 50 \\
2018 & 0.024 & 48 \\
2019 & 0.022 & 44 \\
2020 & 0.021 & 42 \\
2021 & 0.019 & 38 \\
2022 & 0.017 & 34 \\
2023 & 0.016 & 32 \\
2024 & 0.014 & 28 \\
2025 & 0.013 & 26 \\
2026 & 0.011 & 22 \\
2027 & 0.009 & 18 \\
2028 & 0.008 & 16 \\
2029 & 0.006 & 12 \\
2030 & 0.005 & 10 \\
2031 & 0.003 & 6 \\
2032 & 0.002 & 4 \\
$\Sigma$ & 0.3 & 600 \\
\hline
\end{tabular}

Because of supercritical mining, based on the prediction theory of the probabilistic integral method, the total residual subsidence is $m q_{m} \cos \alpha=2000 \times 0.3 \times 1=600 \mathrm{~mm}$, which equals the sum of the annual residual subsidence, as shown in Table 1 . The factor of accumulative annual residual subsidence from 2014 to 2018 is 0.134 , and the corresponding accumulative residual subsidence is $268 \mathrm{~mm}$. The factor of accumulative annual residual subsidence from 2019 to 2032 reaches 0.166 ; thus, the potential residual subsidence in the future would be $332 \mathrm{~mm}$, which accounts for $55.3 \%$ of the total residual surface subsidence. According to the prediction in Table 1, approximately $89 \%$ of the residual subsidence should have occurred by the end of 2026. Although there are no field measurement data of residual subsidence to allow a comparison with in situ results and an assessment of the prediction accuracy, we are able to quantitatively calculate the annual residual subsidence, accumulative residual subsidence, and potential future residual subsidence.

\subsection{Field Study}

Lingxin colliery, located in Yinchuan of Ningxia Hui Autonomous Region, was merged in 2003 with the Ciyao No. 2 mine. From July 2014 to June 2015, the longwall face of 051603 was extracted with roof caving management. The altitudes of the surface and coal seam for $16 \#$ are $1310 \mathrm{~m}$ and $1148 \mathrm{~m}$ above Huanghai sea level, respectively. The average mining depth is $162 \mathrm{~m}$, the thickness of the Quaternary strata is $10 \mathrm{~m}$, and the roof strata rock is sandstone, which has a compressive strength of 17.38 MPa and a tensile strength of 1.70 MPa. Most of the surface is covered by sand with minimal vegetation. The mining thickness is $2.97 \mathrm{~m}$, the dip angle of the coal seam is $14^{\circ}$, and the average mining rate of the longwall face is $1350 \mathrm{~m} / \mathrm{a}$. The strike and dip length of the working face are 1531 and $273 \mathrm{~m}$, respectively. In January 2015, automatic observation stations using GNSS (Global Navigation Satellite System) with one referencing point and two working points were set up, as shown in Figure 7. LX-1-1 is the referencing point and located far from the mining influence of working face 051603. LX-2-2 and LX-2-4 are the working points. Figure 8 shows photographs of the referencing and working points of GNSS measurement stations. 


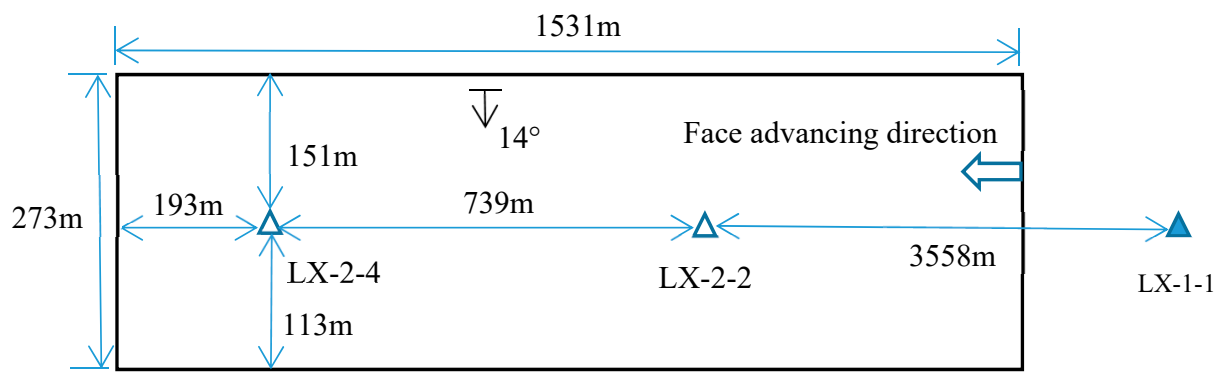

Figure 7. Sketch map of the automatic GNSS measurement stations.

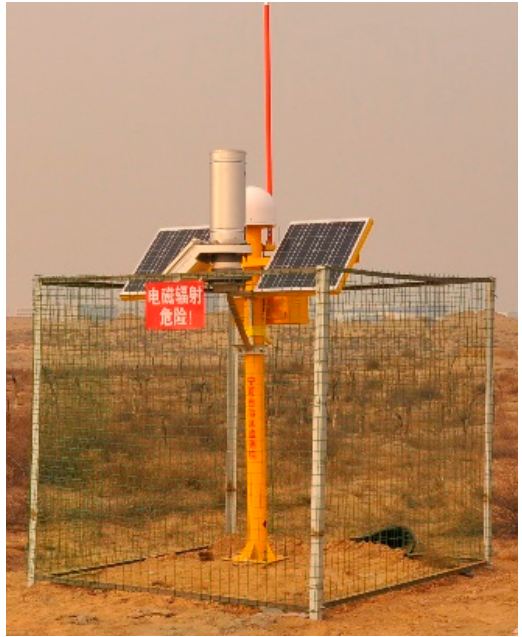

(a) GNSS referencing station

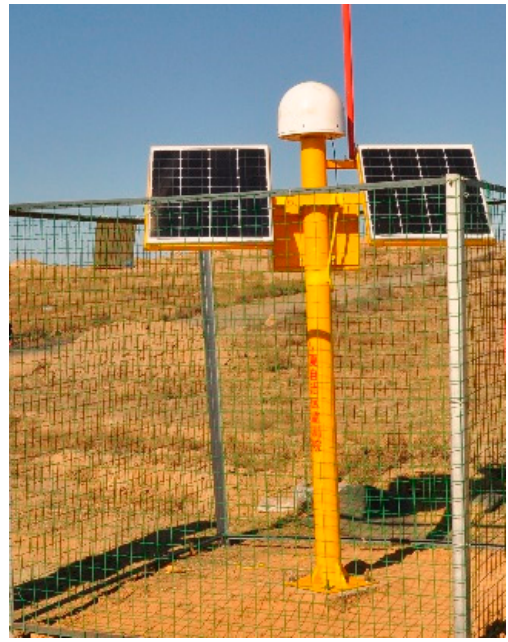

(b) GNSS working points

Figure 8. Photographs of automatic GNSS measuring stations.

From February 2015 to July 2018, surface subsidence data with 154 epochs were obtained (Figure 9). As the established monuments lag the underground mining, the station at LX-2-2 had been impacted by mining at the 051603 working face; therefore, the monitored surface subsidence is a relative subsidence. However, the data from station LX 2-4, located far from the working face, give rise to absolute surface subsidence. In general, the linear decreasing laws of residual surface subsidence display a very similar pattern at both stations, as shown in Figure 9. As mentioned above, the mining depth is shallow, the overburden belongs to weak and soft rock, and surface subsidence is very intense. For station LX-2-4, the initial period is one month, the active period is approximately three months, the weakening period is six months, and the maximum subsidence velocity reaches $108 \mathrm{~mm} /$ day. The total duration of surface movement is ten months; i.e., less than a year. From 28 June 2015 to 28 December 2015, the accumulative subsidence is $29.1 \mathrm{~mm}$ and thus is less than $30 \mathrm{~mm}$ over the six-month period. Therefore, residual surface subsidence begins on 29 December 2015.

In the longwall mining panels that have reached critical mining compared to their mining depth, since the maximum surface subsidence is $2605 \mathrm{~mm}$, the mining thickness is $2.97 \mathrm{~m}$, and the dip angle is $14^{\circ}$, the subsidence factor of $q=0.904$ is determined. The coefficient related to compaction of caved or broken rock is selected as $n=0.5$ and an extreme residual subsidence factor of $q_{m}=0.048$ is obtained. According to Expression (7), the duration of residual subsidence is 3.6a. We substitute $T_{r}=4 \mathrm{a}$ into Expression (5) and derive the factors of annual residual subsidence for the first year, second year, third year, and fourth year of $0.019,0.014,0.010$, and 0.005 , respectively. The corresponding residual subsidence values are $55,40,29$, and $14 \mathrm{~mm}$, respectively. 


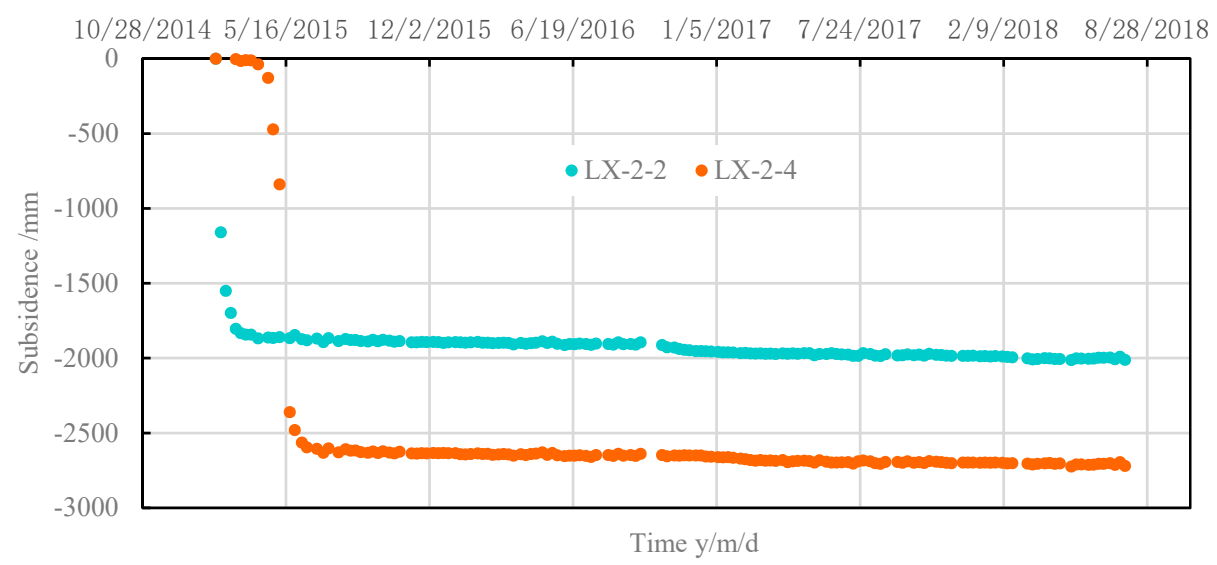

Figure 9. Observed subsidence development curves in Lingxin colliery obtained from two GNSS measurement stations (LX-2-2 and LX-2-4).

As shown in Figure 9, the observed residual subsidence is $24 \mathrm{~mm}$ in the first year (29 December 2015-29 December 2016), $37 \mathrm{~mm}$ in the second year (29 December 2016-29 December 2017), and $22 \mathrm{~mm}$ in the third year (29 December 2017-28 July 2018). The calculated residual subsidence results agree well with the observed data, although the calculated residual subsidence in the first year is slightly larger. Unfortunately, there are no monitored data from 29 July 2018 because the automatic GNSS monitoring stations were deactivated for unknown reasons.

\section{Conclusions}

Under the conditions of the linear monotonic decrease in annual residual surface subsidence and the limit of the sum of annual residual subsidence factors, a model was proposed to calculate the factor of annual residual surface subsidence due to abandoned longwall coal mining. Based on the continuity between surface subsidence in the last year of the weakening period and residual surface subsidence in the first year, we derived an expression to determine the duration of residual surface subsidence. Using the duration and annual residual subsidence factor, we successfully quantified the annual residual subsidence, the accumulative residual subsidence, and the potential future accumulative residual subsidence for given geo-mining conditions. Field measurements indicated a good agreement with the calculated residual subsidence results. This approach can be used to reasonably evaluate the stability and suitability of exhausted or abandoned mining subsidence areas. Therefore, it is highly beneficial for the design of mining subsidence land reclamation and ecological reconstruction.

As is known, the movement of rock strata and ground caused by longwall coal mining is a complicated spatial-temporal process. There are many factors controlling the evolution of movement of caved and fractured zones, such as mining height, mining and roof control methods, rock property and stratigraphic sequence, dip angle, mining sufficiency degree, time factor and so on. With other conditions kept constant, the only coal seam dip angle may result in the shape and height changes of the caved and fractured zone. That is to say that the residual surface subsidence caused by the compaction of the caved and fractured zone would change with the specific geo-mining conditions. The residual surface subsidence factor, expressed as a function of geometric parameters in this paper, is valid for a single longwall panel with sub-horizontal and critical or super-critical mining. The annual greatest damages in the inflection area can be calculated easily by the probabilistic integral method.

On the other hand, the chain pillar between the longwall panels would be designed in order to maintain safety and ventilation. Once the crushed pillars occur due to the actions of long-term load, weathering and water erosion in the underground conditions in the future, the maximum residual surface subsidence would appear in the surface above the crashed pillar. We cannot calculate the coupling residual surface subsidence of a crushed pillar and the compaction of the caved and fractured zone at present. Thus, further aspects now need to be investigated and remain to be solved in the future. 
Author Contributions: Conceptualization, X.C. and Y.Z.; Methodology, X.C. and Y.Z.; analysis, B.Z.; Investigation, G.W. and C.L.; Resources, G.W.; Writing-Original draft preparation, Y.Z.; Writing-Review and editing, B.Z. and C.L.; Supervision, X.C.; Project administration, X.C.; Funding acquisition, X.C. All authors have read and agreed to the published version of the manuscript.

Funding: This research was supported by the National Natural Science Foundation of China (Grant Nos. 51474217, 41671507, 41071328 and 59904005).

Acknowledgments: The authors would like to express their sincere gratitude to the Land Resources Survey and Monitoring Institute of Ningxia Hui Autonomous Region for their data support. In addition, the authors are grateful to the assigned editor and the three anonymous reviewers for their enthusiastic help and valuable comments, which have greatly improved this paper.

Conflicts of Interest: The authors declare no conflict of interest.

\section{References}

1. Peng, S.S. Surface Subsidence Engineering; SME: New York, NY, USA, 1992.

2. Liu, T.Q. Surface Movement, Over Burden Failures and Its Application; Coal Industry Press: Beijing, China, 1981. (In Chinese)

3. Cui, X.; Miao, X.; Wang, J.; Yang, S.; Liu, H.; Song, Y.; Liu, H.; Hu, X. Improved prediction of differential subsidence caused by underground mining. Int. J. Rock Mech. Min. Sci. 2000, 37, 615-627. [CrossRef]

4. Cui, X.M.; Wang, J.C.; Liu, Y.S. Prediction of progressive surface subsidence above longwall coal mining using a time function. Int. J. Rock Mech. Min. Sci. 2001, 38, 1057-1063. [CrossRef]

5. Litwiniszyn, J. The influence of the rate of mining operations on the development of subsidence troughs. Arch. Min. Sci. 2000, 45, 323-331.

6. Brady, B.H.G.; Brown, E.T. Rock Mechanics for Underground Mining, 2nd ed.; Chapman \& Hall: London, UK, 1993.

7. Peng, S.S. Longwall Mining, 2nd ed.; Science Press: Morgantown, WV, USA, 2006.

8. Hejmanowski, R.; Malinowska, A.A. Evaluation of reliability of subsidence prediction based on spatial statistical analysis. Int. J. Rock Mech. Min. Sci. 2009, 46, 432-438. [CrossRef]

9. Cui, X.-M.; Li, C.-Y.; Hu, Q.-F.; Miao, X.-X. Prediction of surface subsidence due to underground mining based on the zenith angle. Int. J. Rock Mech. Min. Sci. 2013, 60, 246-252. [CrossRef]

10. Hejmanowski, R.; Malinowska, A.A. Significance of uncertainty level for modeling of ground deformation ranges. Int. J. Rock Mech. Min. Sci. 2016, 83, 140-148. [CrossRef]

11. Teng, Y.H.; Zhang, J.Y. Evaluation on stability of building foundation over goafs. J. China Coal Soc. 1997, 22, 504-508. (In Chinese)

12. Guo, G.-L.; Deng, K.-Z.; Tan, Z.-X.; Li, F.-C. Study on the prediction method of ground residual subsidence in the deep abandoned longwall goaf and its application. J. Liaoning Tech. Univ. Nat. Sci. Ed. 2002, 21, 1-3. (In Chinese)

13. Zhang, J.Y. Fuzzy comprehensive evaluation method of the foundation stability of new buildings above worked-out areas. J. Univ. Sci. Technol. Beijing 2009, 31, 1368-1372. (In Chinese)

14. Vervoort, A.; Declercq, P. Surface movement above old coal longwalls after mine closure. Int. J. Min. Sci. Technol. 2017, 27, 481-490. [CrossRef]

15. Lee, D.-K.; Mojtabai, N.; Lee, H.-B.; Song, W.-K. Assessment of the influencing factors on subsidence at abandoned coal mines in South Korea. Environ. Earth Sci. 2013, 68, 647-654. [CrossRef]

16. Bell, F.G.; Bruyn, I.A. Subsidence problems due to abandoned pillar workings in coal seams. Bull. Eng. Geol. Environ. 1999, 57, 225-237. [CrossRef]

17. Li, H.Z.; Zhao, B.C.; Guo, G.L. The influence of an abandoned goaf on surface subsidence in an adjacent working coal face: A prediction method. Bull. Eng. Geol. Environ. 2018, 77, 305-315. [CrossRef]

18. Swift, G.M.; Reddish, D.J. Stability problems associated with an abandoned ironstone mine. Bull. Eng. Geol. Environ. 2002, 61, 227-239.

19. Guéguen, Y.; Deffontaines, B.; Fruneau, B.; Marwan, A.; de Michele, M.; Raucoules, D.; Guise, Y.; Planchenault, J. Monitoring residual mining subsidence of Nord/Pas-de-Calais coal basin from differential and Persistent Scatterer Interferometry (Northern France). J. Appl. Geophys. 2009, 69, 24-34. [CrossRef] 
20. Cuenca, M.C.; Hooper, A.J.; Hanssen, R.F. Surface deformation induced by water influx in the abandoned coal mines in Limburg, The Netherlands observed by satellite radar interferometry. J. Appl. Geophys. 2013, 88, 1-11. [CrossRef]

21. Kamila, P.F.; Andrzej, B. Integration of DInSAR and SBAS Techniques to Determine Mining-Related Deformations Using Sentinel-1 Data: The Case Study of Rydułtowy Mine in Poland. Remote Sens. 2020, 12, 242. [CrossRef]

22. Oh, H.J.; Lee, S. Integration of ground subsidence hazard maps of abandoned coal mines in Samcheok, Korea. Int. J. Coal Geol. 2011, 86, 58-72. [CrossRef]

23. Oh, H.-J.; Ahn, S.-C.; Choi, J.-K.; Lee, S. Sensitivity analysis for the GIS-based mapping of the ground subsidence hazard near abandoned underground coal mines. Environ. Earth Sci. 2011, 64, 347-358. [CrossRef]

24. Helm, P.R.; Davie, C.T.; Glendinning, S. Numerical modelling of shallow abandoned mine working subsidence affecting transport infrastructure. Eng. Geol. 2013, 154, 6-19. [CrossRef]

25. Tong, L.; Liu, L.; Yu, Q. Tunneling in abandoned coal mine areas: Problems, impacts and protection measures. Tunnell. Undergr. Space Technol. 2013, 38, 409-422. [CrossRef]

26. Komnitsas, K.; Guo, X.Y.; Li, D.L. Mapping of soil nutrients in an abandoned Chinese coal mine and waste disposal site. Miner. Eng. 2010, 23, 627-635. [CrossRef]

27. Pentaria, D.; Typoua, J.; Goodarzib, F.; Foscolos, A.E. Comparison of elements of environmental concern in regular and reclaimed soils, near abandoned coal mines Ptolemais-Amynteon, northern Greece: Impact on wheat crops. Int. J. Coal Geol. 2006, 65, 51-58. [CrossRef]

28. Bullock, S.E.T.; Bell, F.G. Some problems associated with past mining at a mine in the Witbank coalfield, South Africa. Environ. Geol. 1997, 33, 61-71. [CrossRef]

29. Bell, F.G.; Bullock, S.E.T.; Halbich, T.F.J.; Lindsay, P. Environmental impacts associated with an abandoned mine in the Witbank Coalfield, South Africa. Int. J. Coal Geol. 2001, 45, 195-216. [CrossRef]

30. Mishra, S.K.; Hitzhusen, F.J.; Sohngen, B.L.; Guldmann, J.M. Costs of abandoned coal mine reclamation and associated recreation benefits in Ohio. J. Environ. Manag. 2012, 100, 52-58. [CrossRef]

31. Guo, G.L.; Deng, K.Z.; Chang, J. Study on the foundation settlement of heavy buildings above mine goafs. J. China Univ. Min. Technol. 1996, 25, 54-57. (In Chinese)

32. Wang, Z.S.; Deng, K.Z. Analysis of surface residual deformation and stability evaluation of buildings foundation in old goaf. Coal Sci. Technol. 2015, 43, 133-137. (In Chinese)

33. Hu, H.F.; Zhao, Y.S.; Kang, J.R.; Liang, W.G. Related laws and verification of mined-out area span, time and residual deformation. Chin. J. Rock Mech. Eng. 2018, 27, 65-71. (In Chinese)

34. Miao, X.; Cui, X.M.; Wang, J.-A.; Xu, J.L. The height of fractured water-conducting zone in undermined rock strata. Eng. Geol. 2011, 120, 32-39. [CrossRef]

35. Palchik, V. Bulking factors and extents of caved zones in weathered overburden of shallow abandoned underground workings. Int. J. Rock Mech. Min. Sci. 2015, 79, 227-240. [CrossRef]

36. Yavuz, H. An estimation method for cover pressure re-establishment distance and pressure distribution in the goaf of longwall mines. Int. J. Rock Mech. Min. Sci. 2004, 41, 193-205. [CrossRef]

37. Technical Identification Committee for Coal Mining Damage. Subsidence Prediction Method for Coal Mining; MJ/T2014-0001; Coal Industry Standard of the People's Republic of China: Beijing, China, 2014. (In Chinese)

38. State Administration of Work Safety; National Coal Ming Safety Administration; National Energy Administration; National Railway Administration. Regulations of Coal Mining under Buildings, Water Bodies, Railway and Safety Pillar Design; Coal Industry Press: Beijing, China, 2017. (In Chinese)

(C) 2020 by the authors. Licensee MDPI, Basel, Switzerland. This article is an open access article distributed under the terms and conditions of the Creative Commons Attribution (CC BY) license (http://creativecommons.org/licenses/by/4.0/). 